Article

\title{
Potential of Polymeric Films Loaded with Gold Nanorods for Local Hyperthermia Applications
}

\author{
Álvaro Cárcamo-Martínez ${ }^{1}$, Juan Domínguez-Robles ${ }^{1}$, Brónach Mallon ${ }^{1}$, Md. Taifur Raman ${ }^{2}$, \\ Ana Sara Cordeiro ${ }^{1} \mathbb{D}$, Steven E. J. Bell ${ }^{2}$, Eneko Larrañeta ${ }^{1}\left[\right.$ and Ryan F. Donnelly ${ }^{1, * \mathbb{D}}$ \\ 1 School of Pharmacy, Queen's University Belfast, 97 Lisburn Road, Belfast BT9 7BL, UK; \\ a.carcamo@qub.ac.uk (A.C.-M.); j.dominguezrobles@qub.ac.uk (J.D.-R.); bmallon14@qub.ac.uk (B.M.); \\ a.cordeiro@qub.ac.uk (A.S.C.); e.larraneta@qub.ac.uk (E.L.) \\ 2 School of Chemistry and Chemical Engineering, Queen's University Belfast, Belfast BT9 5AG, UK; \\ t.rahman@qub.ac.uk (M.T.R.); s.bell@qub.ac.uk (S.E.J.B.) \\ * Correspondence: r.donnelly@qub.ac.uk
}

Received: 27 February 2020; Accepted: 20 March 2020; Published: 23 March 2020

\begin{abstract}
Current strategies for the treatment of superficial non-melanoma skin cancer (NMSC) lesions include topical imoquimod, 5-fluorouracil, and photodynamic therapy. Although these treatments are effective, burning pain, blistering, and dermatitis have been reported as frequent side effects, making these therapies far from ideal. Plasmonic materials have been investigated for the induction of hyperthermia and use in cancer treatment. In this sense, the effectiveness of intratumorally and systemically injected gold nanorods (GnRs) in inducing cancer cell death upon near-infrared light irradiation has been confirmed. However, the in vivo long-term toxicity of these particles has not yet been fully documented. In the present manuscript, GnRs were included in a crosslinked polymeric film, evaluating their mechanical, swelling, and adhesion properties; moreover, their ability to heat up neonatal porcine skin (such as a skin model) upon irradiation was tested. Inclusion of GnRs into the films did not affect mechanical or swelling properties. GnRs were not released after film swelling, as they remained entrapped in the polymeric network; moreover, films did not adhere to porcine skin, altogether showing the enhanced biocompatibility of the material. GnR-loaded films were able to heat up the skin model over $40^{\circ} \mathrm{C}$, confirming the potential of this system for non-invasive local hyperthermia applications.
\end{abstract}

Keywords: non-melanoma skin cancer; hyperthermia; gold nanorods; polymeric films; near infrared light; heating studies

\section{Introduction}

Incidence of non-melanoma skin cancers (NMSC) is increasing worldwide. Reports show that in the UK, 47,000 new NMSC cases are diagnosed every year, and since the early 90s, incidence rates have increased by more than two-and-a-half times (163\%) [1]. A similar trend has been reported in Germany [2], Denmark [3], Canada [4], the USA [5], and Australia [6], among other countries. Although death is rare, treatment of NMSC results in a considerable burden on healthcare systems [79]. For superficial lesions, non-invasive approaches involving topical imoquimod, 5-fluorouracil, and photodynamic therapy are preferred [10-12]. Although effective for this type of lesion, side effects such as itching, burning pain, erythema, dermatitis, blistering, necrosis, and pruritus have been reported as highly frequent [10,13], making these treatments unpleasant and far from ideal.

The primary and adjunctive treatment of cancers by induced hyperthermia is a well-established but burgeoning field of medical research. In this sense, temperatures in tumor-loaded tissues are elevated to more than $43^{\circ} \mathrm{C}$ by selective or non-selective application of microwave, radio, ultrasound, 
alternating magnetic, infrared, or visible radiation [14,15], triggering either necrosis or apoptosis [16,17]. In the first case, when the temperature is raised above $50^{\circ} \mathrm{C}$, it disrupts the plasma membrane, causing leaking of cellular components, and thereby inflammation, metastasis, and harm to surrounding normal tissue could take place [16]. On the other hand, induction of apoptosis takes place when the temperature increases to $43-50{ }^{\circ} \mathrm{C}$. Apoptosis is a standard part of the cell cycle, although it is inhibited in cancer cells to allow for unregulated growth. Hence, as it is an internal process, no extracellular leakage or inflammation is triggered [17], and therefore, hyperthermia should be modulated towards an apoptotic response.

Interest in gold nanorods (GnRs) as thermal agents is due to their ability to emit heat by absorbing near infrared light, on the basis of the phenomenon of localized surface plasmon resonance (LSPR) $[18,19]$. The GnR spectra exhibit two plasmon resonances: the transverse plasmon is the result of excitation across the nanorod diameter and the longitudinal plasmon is due to excitation along the nanorod length [20]. Hence, the diameter of GnRs can be an important differentiation factor for their applications; scattering becomes dominant for thicker GnRs, and so they are favorable for biolabeling and contrast purposes. On the other hand, absorption predominates in thin GnRs, making them well-suited for photothermal applications that require high photon-to-heat conversion efficiency [21,22].

Investigations have shown the effectiveness of photothermal therapy using intratumorally and systemically injected GnRs in inducing cancer cell death $[16,18,23,24]$. However, research addressing the safety and toxicity of GnRs is still controversial [23,25-27]. The surface chemistry of GnRs has been recently linked to toxicity in cultured cells and mice [23]. This could be attributed mainly to the surfactant used in the synthesis of GnRs, cetyltrimethylammonium bromide (CTAB), which has been associated with cytotoxicity at micromolar concentrations $[18,28]$. Hence, strategies to increase biocompatibility have been followed, such as functionalization, of the surfaces of GnRs with polymers, including poly(acrylic acid), poly(allylamine) hydrochloride, and poly(styrene)sultanate, or by exchanging CTAB with a less toxic ligand, such as mercaptohexadenoic acid or poly(ethylene)glycol [16,21,23,28]. Furthermore, surface modification of GnRs with manganese dioxide or anti-nucleolin aptamer (AS1411), among others, has been explored to increase the performance of photothermal conversion [29]. However, the in vivo long-term toxicity of these functionalized GnRs has not yet been fully documented.

Until further and high-level evidence regarding the safety and toxicological profile of GnRs is gathered, approaches where body exposure to these particles is limited or avoided should be used. In the present work, CTAB-GnRS were prepared by the seed-mediated method [22] and functionalized with thiolated poly(ethylene) glycol (mPEG-SH) [30]. Both types of GnRs were characterized and then included in polymeric crosslinked films, evaluating their effect on film structural properties through mechanical, swelling, and thermal analyses. Finally, the heating capacity of films upon laser irradiation and the transfer of heat to a skin model were tested to evaluate the possible application of GnR-loaded films for local skin hyperthermia.

\section{Materials and Methods}

\subsection{Materials}

Gantrez ${ }^{\circledR}$ S-97, copolymer of methyl vinyl ether and maleic acid (PVME/MA), with a molar mass of 1,200,000, was donated by Ashland (Barcelona, Spain). Tetrachloroauric acid $\left(\mathrm{HAuCl}_{4}\right)$, cetyltrimethylammonium bromide $(\mathrm{CTAB})$, sodium borohydride $\left(\mathrm{NaBH}_{4}\right), \mathrm{L}$-ascorbic acid, poly(ethylene glycol) (PEG) $200 \mathrm{Da}$, and poly(ethylene glycol)methyl ether thiol (mPEG-SH) were purchased from Sigma-Aldrich (St. Louis, MO, USA). The 5-Bromosalicylic acid (5-BrSA) and silver nitrate $\left(\mathrm{AgNO}_{3}\right)$ were purchased from Alfa Aesar (Lancashire, UK). Neonate porcine skin from stillborn piglets was used for heating studies, with full-thickness skin samples being obtained in less than $24 \mathrm{~h}$ post-mortem, rinsed in phosphate buffered saline (PBS), trimmed to a $350 \mu \mathrm{m}$ thickness using 
an electric dermatome (Integra Life Sciences ${ }^{\mathrm{TM}}$ Padgett Instruments, Princeton, NJ, USA), and cut into $2 \times 2 \mathrm{~cm}^{2}$ pieces.

\subsection{Synthesis and Characterization of Gold Nanorods (GnRs)}

GnRs were prepared according to a previously reported method [22]. All the glassware was cleaned with aqua regia, rinsed with water, and dried before use. A seed solution was prepared by diluting $2.5 \mathrm{~mL}$ of $\mathrm{HAuCl}_{4} 1 \mathrm{mM}$ with $2.5 \mathrm{~mL}$ of purified water and adding $5 \mathrm{~mL}$ of CTAB $0.2 \mathrm{M}$ under magnetic stirring. A dilution of $0.6 \mathrm{~mL}$ of $\mathrm{NaBH}_{4} 0.01 \mathrm{M}$ with purified water, making up $1 \mathrm{~mL}$, was injected into the previous mixture under intense stirring $(1200 \mathrm{rpm})$ for $2 \mathrm{~min}$. The final seed solution was kept undisturbed at room temperature for $30 \mathrm{~min}$ before use. The growth solution was prepared by mixing $9 \mathrm{~g}$ of $\mathrm{CTAB}$ and $1.1 \mathrm{~g}$ of $5-\mathrm{BrSA}$ with $250 \mathrm{~mL}$ purified water at $50-70{ }^{\circ} \mathrm{C}$. After complete dissolution, the mixture was cooled down to $30^{\circ} \mathrm{C}$. Then, $12 \mathrm{~mL}$ of $\mathrm{AgNO}_{3} 4 \mathrm{mM}$ was added and the solution was kept undisturbed at $30^{\circ} \mathrm{C}$ for $15 \mathrm{~min}$. Then, $250 \mathrm{~mL}$ of $\mathrm{HAuCl}_{4} 1 \mathrm{mM}$ was added and the solution was stirred for $15 \mathrm{~min}$ at $400 \mathrm{rpm}$. Afterwards, $2 \mathrm{~mL}$ of L-ascorbic acid $0.064 \mathrm{M}$ was injected, and the solution was mixed vigorously for $30 \mathrm{~s}$ until it became colorless. To prepare the GnRs, $0.8 \mathrm{~mL}$ of the seed solution was injected into the growth solution and stirred for $30 \mathrm{~s}$. The mixture, CTAB-GnRs, was left undisturbed at $30^{\circ} \mathrm{C}$ for $12 \mathrm{~h}$.

2.2.1. Functionalization of GnRs by Thiolated Poly(ethylene) Glycol (mPEG-SH) and Cetyltrimethylammonium Bromide (CTAB) Removal

Then, $50 \mathrm{~mL}$ of CTAB-GnRs was centrifuged at $8500 \mathrm{rpm}$ for $45 \mathrm{~min}$, then the precipitate was resuspended in purified water and centrifuged again in order to remove part of the non-bounded CTAB. The final precipitate was resuspended in $1.2 \mathrm{~mL}$ of purified water, mixed with $3.8 \mathrm{~mL}$ of $\mathrm{mPEG}-\mathrm{SH} 2$ $\mathrm{mM}$, and kept undisturbed at room temperature for $24 \mathrm{~h}$. In order to further wash and completely remove the $\mathrm{CTAB}, \mathrm{GnRs}$ were dialyzed against water using a regenerated cellulose membrane, namely SnakeSkin ${ }^{\mathrm{TM}}$ Dialysis Tubing 7K molecular weight cut-off (MWCO) (ThermoFisher Scientific, Waltham, MA, USA), for $24 \mathrm{~h}$ with several replacements of water. After dialysis, samples of pegylated GnRs (PEG-GnRs) were mixed with water to make up a volume of $50 \mathrm{~mL}$.

\subsubsection{UV Spectrum of GnRs}

CTAB and PEG-GnRs were assessed with a UV microplate FluoStar Optima fluorescence spectrophotometer (BMG Labtech, Ortenberg, Germany) in order to observe their near-infrared (NIR) absorbance properties. All samples were diluted with distilled water in a 1:1 proportion and the UV spectrum between 220 and $1000 \mathrm{~nm}$ was recorded.

\subsubsection{Transmission Electron Microscopy Images of GnRs}

A transmission electron microscope (TEM) was used to measure the length and width of CTAB-GnRs and PEG-GnRs. For this purpose, $10 \mu \mathrm{L}$ of washed samples was deposited on copper grids and evaluated using a TEM JEM-1400Plus (JEOL, Tokyo, Japan).

\subsubsection{Z Potential of GnRs}

CTAB and PEG-GnRs suspensions were assessed with a NanoBrook Omni particle sizer and zeta potential analyzer (Brookhaven, New York, NY, USA) to determine their zeta potential, measuring each sample for three cycles.

\subsubsection{Raman Spectroscopy Characterization of CTAB and Pegylated GnRs (PEG-GnRs)}

GnRs were evaluated with a RamanMicro ${ }^{\mathrm{TM}} 300$ microscope equipped with a RamanStation R3 (PerkinElmer, Waltham, MA, USA) to confirm the replacement of CTAB by mPEG-SH. First, $100 \mu \mathrm{L}$ of each sample was placed on a glass microscope slide, which was previously covered with aluminium 
foil, and left to dry. Each sample was exposed 4 times for $5 \mathrm{~s}$ each, and the spectrum from $0 \mathrm{~cm}^{-1}$ to $3681 \mathrm{~cm}^{-1}$ was recorded.

\subsubsection{Gold Quantification in GnRs}

The gold content in GnR samples was assessed by inductively coupled plasma optical emission spectroscopy (ICP-OES) using a 5100 Synchronous Vertical Dual View ICP (Agilent, Santa Clara, CA, USA). CTAB-GnRs samples measuring $50 \mathrm{~mL}$ were centrifuged at $8500 \mathrm{rpm}$ for $45 \mathrm{~min}$, the precipitate was resuspended in purified water, and then centrifuged again to remove part of the non-bounded $\mathrm{CTAB}$ and non-reacted materials. In contrast, PEG-GnRs were used directly. Samples measuring 2.5 $\mathrm{mL}$ of GnRs were mixed with nitric acid $65 \%$, hydrochloric acid $37 \%$, and purified water, giving a final volume of $50 \mathrm{~mL}$. The solution was kept at $60^{\circ} \mathrm{C}$ for $2 \mathrm{~h}$ to digest and dissolve all materials. Instruments were calibrated using gold standard solutions and samples were measured afterwards in triplicate.

\subsection{Fabrication and Characterization of Polymeric Films Loaded with GnRs}

Polymeric films containing CTAB-GnRs or PEG-GnRs were fabricated using a mixture (\%w/w) of $25 \%$ Gantrez ${ }^{\circledR}$ S-97, 10\% PEG 200 Da, and q.s. of the concentrated GnRs suspension. For CTAB-GnRs, $50 \mathrm{~mL}$ of CTAB-GnRs suspension was centrifuged at $8500 \mathrm{rpm}$ for $45 \mathrm{~min}$ and resuspended in the same volume of purified water, centrifuged again, and then concentrated by completing the volume until it reached $5 \mathrm{~mL}$. For PEG-GnRs, the suspension obtained in Section 2 was used directly after dialysis, making up the final volume to $5 \mathrm{~mL}$, as well for comparison purposes. Films without GnRs were also fabricated as controls, using only distilled water instead of GnR suspension. Obtained gels were centrifuged at $5000 \mathrm{rpm}$ for $15 \mathrm{~m}$ to remove air bubbles and then cast on a $9 \mathrm{~cm}^{2}$ siliconized release liner. Films were left to dry at room temperature for 2 days, cut in approximately $1 \mathrm{~cm}^{2}$ pieces and then crosslinked in an oven at $80^{\circ} \mathrm{C}$ overnight. Films were visualized using digital and a Tabletop TM3030 transmission scanning electron microscope (Hitachi, Tokyo, Japan) and then measured in terms of thickness, area and weight.

\subsubsection{Mechanical Properties of Polymeric Films}

The flexibility of polymeric films and the effect of GnRs on this factor was assessed using a Texture Analyzer TA.XT-Plus (Stable Micro Systems, Surrey, UK), as shown in Figure 1. Briefly, films were placed on top of two aluminium blocks, leaving a distance between the blocks of $7 \mathrm{~mm}$. An aluminium probe was placed on the mobile part of the texture analyzer and moved towards the film at a speed of $1 \mathrm{~mm} / \mathrm{s}$ while the force and distance travelled by the probe were recorded [31]. The force at the break of each film was determined by looking at the maximum force on the force $(\mathrm{N})$ vs. distance $(\mathrm{mm})$ graph.

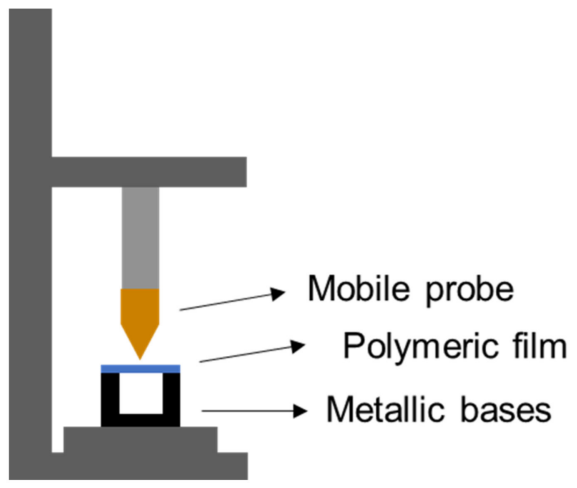

Figure 1. Schematic representation of the texture analyzer setup used to study the mechanical properties of films by recording the force at the breaks of films. 


\subsubsection{Adhesion of Polymeric Films to Neonate Porcine Skin}

The adhesive properties of crosslinked films were evaluated using a texture analyzer set in adhesive test mode. Two pieces of dermatomed neonate porcine skin (350 $\mu \mathrm{m}$ thickness each) were placed facing each other's dermis, pinned into a poly(urethane) foam, and located on the base of the equipment. Films $\left(1 \mathrm{~cm}^{2}\right)$ were attached to the mobile probe using double-sided adhesive tape. Before starting the studies, $20 \mu \mathrm{L}$ of phosphate buffered saline (PBS) were placed on top of porcine skin and the mobile probe was immediately lowered. A force of $5 \mathrm{~N}$ for $2 \mathrm{~min}$ was applied and then the probe was move upwards at a speed of $0.5 \mathrm{~mm} \cdot \mathrm{s}^{-1}$. Adhesion was recorded as the maximal force required to detach the sample from the surface of the skin.

\subsubsection{Swelling of Polymeric Films on Phosphate Buffered Saline (PBS)}

The initial dry weight of the polymeric films was recorded $\left(m_{0}\right)$ before the films were immersed in $5 \mathrm{~mL}$ of PBS for 5, 15, 30, and $60 \mathrm{~min}$. At each time point, films were removed, the excess of PBS on the surface was dried using a paper towel, and the films were weighed again $\left(m_{t}\right)$. The swelling index (SI) of each film was calculated according to the Equation (1). Digital pictures of films at each time were also taken.

$$
S I=\left(m_{t}-m_{0}\right) \times 100 / m
$$

\subsubsection{Thermal Analysis of Polymeric Films}

Raw materials used for the fabrication of films (Gantrez ${ }^{\circledR}$ S-97 and PEG 200 Da) and prepared films were evaluated using a 2920 differential scanning calorimeter (DSC) (TA Instruments, Surry, UK). Samples weighing between 3 and $10 \mathrm{mg}$ were placed in aluminium pans and then sealed with an aluminium lid. The samples were heated from 50 to $350{ }^{\circ} \mathrm{C}$, at a rate of $10^{\circ} \mathrm{C} / \mathrm{min}$. The heat flow (mW) on samples as a function of temperature was obtained. Same materials and films were also tested using a TGA Q500 thermogravimetric analyzer (TA Instruments, Elstree, UK) by placing $10 \mathrm{mg}$ of sample on aluminium pans. Heating was performed from 50 to $400{ }^{\circ} \mathrm{C}$, increasing temperature at a rate of $10^{\circ} \mathrm{C} / \mathrm{min}$. The weight loss (as percentage) of the samples as a function of temperature was obtained.

\subsubsection{Fourier Transform Infrared Spectroscopy of Polymeric Films}

The spectra of polymeric films were recorded using a Spectrum Two instrument (PerkinElmer, Waltham, MA, USA) equipped with an attenuated total reflectance (ATR) accessory. The spectra were recorded as the mean of 20 scans from 450 to $4000 \mathrm{~cm}^{-1}$ using a resolution of $4 \mathrm{~cm}^{-1}$, and the \% transmittance versus wavelength was recorded. Subsequently, the films were immersed in $10 \mathrm{~mL}$ of $\mathrm{NaOH} 5 \mathrm{M}$, dried, and the spectrum was again recorded.

\subsubsection{GnRs Release from Polymeric Films by Immersion on PBS}

Films loaded with GnRs were immersed in $5 \mathrm{~mL}$ of PBS for different times $(5,15,30$, and $60 \mathrm{~min})$. At each timepoint, films were removed and the absorbance of an aliquot of PBS (without dilutions) was directly measured on the spectrophotometer. For comparison purposes, a film without GnRs was also tested.

\subsection{Thermal Studies of GnR-Loaded Polymeric Films}

The thermal capacity of polymeric films loaded with GnRs was evaluated using a $2 \mathrm{~W} / \mathrm{cm}^{2} 808 \mathrm{~nm}$ infrared laser (Sunshine-Electronics, Guangdong, China) and a FLIR E8 infrared thermal imaging camera (FLIR, Täby, Sweden), as shown in Figure 2A. Films were placed at a distance of $16 \mathrm{~cm}$ from the laser using a sample holder that left $1 \mathrm{~cm}^{2}$ of each sample exposed to the laser. The thermal camera was placed at a distance of $2 \mathrm{~cm}$ from films. The initial temperature of each film was recorded and then films were irradiated for 3 cycles of $10 \mathrm{~s}$, cooled down between each cycle, and the temperature 
reached at each time was recorded. A control sample (film without GnRs) was irradiated for 10, 20, and $30 \mathrm{~s}$, with temperatures recorded post-irradiation.
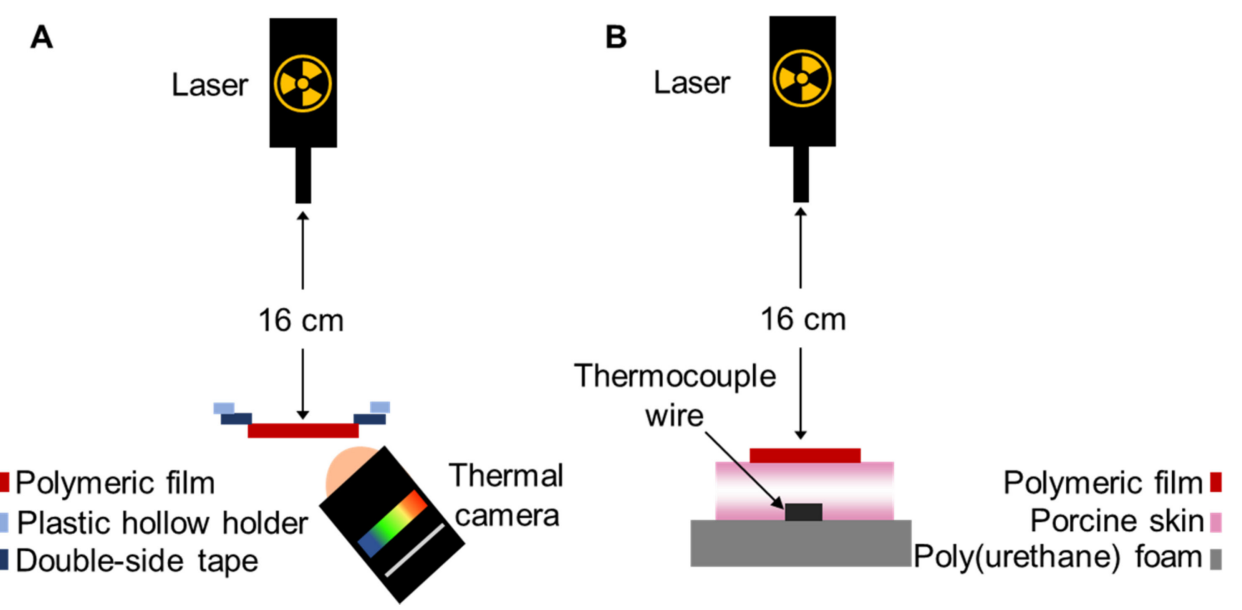

Figure 2. Experimental setup for thermal studies of gold-nanorod-loaded (GnR-loaded) films (A). Distance between laser and films was kept at $16 \mathrm{~cm}$. Laser wavelength was $808 \mathrm{~nm}$, with a power of $2 \mathrm{~W}$, and film irradiation lasted for $15 \mathrm{~s}$. Experimental setup for thermal studies using neonate porcine skin (B). The distance between the laser and polymeric film was kept at $16 \mathrm{~cm}$. Thermocouple wire was placed underneath the porcine skin. The laser wavelength was $808 \mathrm{~nm}$, with a power of $2 \mathrm{~W}$, and films irradiation lasted for $15 \mathrm{~s}$.

\subsection{Heating Capacity of Polymeric Films on Neonate Porcine Skin}

The capacity of polymeric films loaded with GnRs to heat up neonate porcine skin was evaluated using the setup described in Figure 2B. Two pieces of trimmed skin ( $350 \mu \mathrm{m}$ in thickness each) facing each other's dermis were placed on top of a polystyrene foam and pinned. A thermocouple wire was placed underneath the porcine skin and a thermal camera was used to visualize heating from above as well. A NIR laser ( $2 \mathrm{~W}$ and $808 \mathrm{~nm}$ wavelength) was placed above the porcine skin and kept at $16 \mathrm{~cm}$ distance. Porcine skin was kept moist by adding $1 \mathrm{~mL}$ of fresh PBS and then placing the polymeric films on top. The initial temperature was recorded with both the thermal camera and an OMEGAETTE ${ }^{\circledR}$ HH314A temperature meter (Omega, Manchester, UK). Then, films were irradiated for $15 \mathrm{~s}$ and temperatures were reached at 15, 30, 40, 50, 60, and $120 \mathrm{~s}$, which were recorded with both instruments.

\subsection{Statistical Analyses}

Data is shown as mean \pm standard deviation (SD) from triplicate measurements, unless otherwise stated. Differences between study groups were assessed for significance using one-way analysis of variance (ANOVA), followed by a multiple comparisons test (Tukey's test). The threshold for significance was $p<0.05$. Statistical analysis was performed using Prism 7 (GraphPad Software, San Diego, CA, USA).

\section{Results and Discussion}

\subsection{Synthesis and Characterization of GnRs}

GnRs were prepared using a previously reported seed-mediated growth method [22], where small gold nanoparticle seeds were added to an aqueous growth solution consisting of a mixture of ionic silver, ionic gold $\left(\mathrm{AuCl}_{4}{ }^{-}\right)$, weak reductant (ascorbic acid), and surfactant (CTAB). CTAB has been proven to cause cytotoxicity, complicating the use of GnRs for biomedical applications [23]. Hence, samples of CTAB-GnRs were taken and the CTAB was removed by functionalization with mPEG-SH. Figure 3 shows prepared GnRs, as well as their absorption spectra. 
A

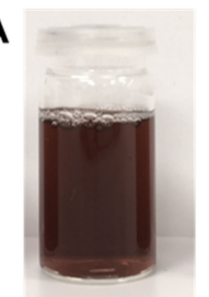

CTAB-GnRs

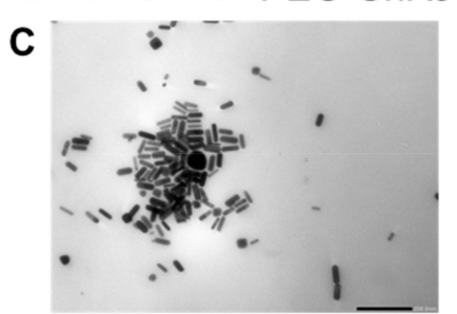

D

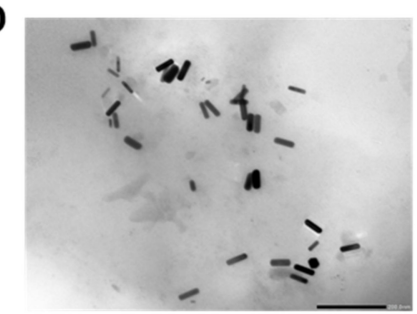

B

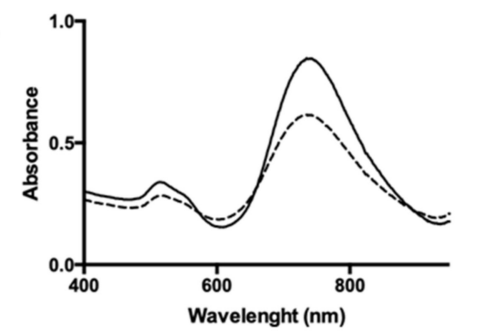

E

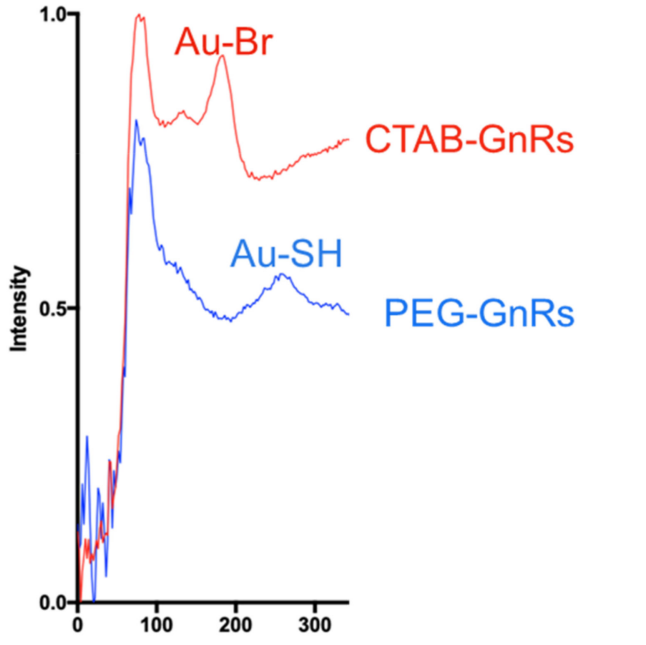

Figure 3. Representative images of GnR samples (A). Absorbance spectrum of GnRs within the near-infrared (NIR) spectrum (B). Representative transmission electron microscopy (TEM) images of cetyltrimethylammonium bromide GnRs (CTAB-GnRs) (C) and pegylated GnRs (PEG-GnRs) (D) (scale bar represents $200 \mathrm{~nm}$ ). Raman spectroscopy of GnRs (E).

The maximum absorbance in the NIR region for both CTAB and PEG-GnRs was at $735 \mathrm{~nm}$. It can also be seen in the absorbance spectrum that PEG-GnRs had a lower absorbance in both peaks in comparison to the original batch, but no shift in the peaks could be seen. Since the surface plasmon resonance of GnRs depends on their size and aspect ratio [32,33], spectrum results suggest that functionalization with mPEG-SH did not lead to aggregation of particles, and the decrease in absorbance could be attributed to the dialysis process, where some of the particles could have diffused into the dialysis media.

TEM images of the different samples showed that rod-like particles were achieved and that this shape was not changed after PEG functionalization (Figure 3). The dimensions of GnRs are shown in Table 1. CTAB and PEG-GnRs have similar lengths and widths, ranging from 49 to $53 \mathrm{~nm}$ in length and 14 to $19 \mathrm{~nm}$ in width, making them ideal for hyperthermia purposes, as absorption instead of scattering of NIR light is favored in GnRs below $20 \mathrm{~nm}$ width [22,34].

Table 1. Physical characterization of GnRs (mean \pm SD, $n=5$ ).

\begin{tabular}{cccc}
\hline Sample & Length $(\mathbf{n m})$ & Width $(\mathbf{n m})$ & Aspect Ratio \\
\hline CATB-GnRs & $53.91 \pm 7.45$ & $17.70 \pm 2.69$ & $3.11 \pm 0.73$ \\
PEG-GnRs & $53.00 \pm 7.50$ & $15.02 \pm 2.32$ & $3.60 \pm 0.78$ \\
\hline
\end{tabular}

CTAB-GnRs exhibited a positive charge of $40.04 \pm 3.98 \mathrm{mV}$ (mean \pm S.D., $\mathrm{n}=9$ ), due to the cationic nature of the quaternary ammonium bromide moiety of the surfactant [23,30]. The Z-potential of PEG-GnRs decreased to $-12.99 \pm 3.03 \mathrm{mV}$, suggesting that CTAB was removed from the particles and replaced by mPEG-SH. Moreover, the results obtained in the Raman spectroscopy showed peaks at 184 and $254 \mathrm{~cm}^{-1}$, which have been associated with $\mathrm{Au}-\mathrm{Br}$ and $\mathrm{Au}-\mathrm{S}$ bond formation, respectively, also confirming the replacement of CTAB by mPEG-SH $[20,30]$. 
The gold content in samples of CTAB and PEG-GnRs was $76.3 \pm 4.4$ and $41.7 \pm 7.3 \mu \mathrm{g} / \mathrm{mL}$, respectively. Since the theoretical concentration of gold in the pure suspension was $1 \mathrm{mg} / \mathrm{mL}$, the percentage of gold converted into GnRs was $7.63 \%$ and $4.17 \%$ for CTAB and PEG, respectively, which is within ranges previously reported when the seed-mediated method is used [35,36]. The decrease of metallic gold content in the pegylated samples could be a consequence of the CTAB washing and dialysis step, as some of the GnRs could have been lost during the process.

\subsection{Preparation and Characterization of Polymeric Films Loaded with GnRs}

Polymeric films loaded with GnRs were fabricated by casting a mix of Gantrez ${ }^{\circledR}$ S-97, PEG 200 $\mathrm{Da}$, and GnRs onto siliconized paper. After 2 days of drying, films were flexible enough to be removed from the release liner without any damage and were subsequently crosslinked in an oven at $80^{\circ} \mathrm{C}$ overnight. In fact, more complex geometries could be prepared by casting the gels in different molds or by simply cutting them before crosslinking, as shown in Figure 4B. Since the morphology of NMSC lesions is variable and does not always exhibit a flat surface [11], films could be tailored to each patient. As happened with the different GnRs samples, differences in color can also be seen on the films due to the different optical properties. On SEM images, it can be seen that polymer and crosslinking agents are fully mixed in a non-porous structure in all films prepared. The thickness, area, and weight of films were recorded (Table 2), and since the same amount of gel was used to prepare the films, similar values were obtained for the aforementioned parameters.

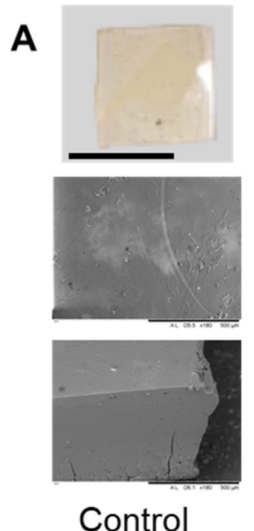

Control
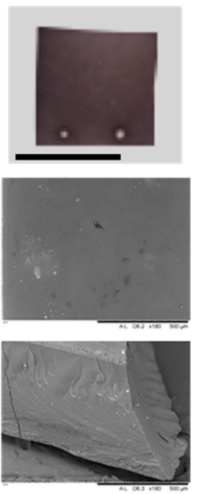

CTAB-GnRs films
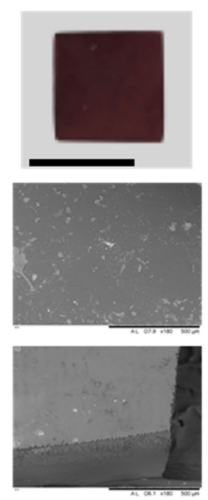

PEG-GnRs

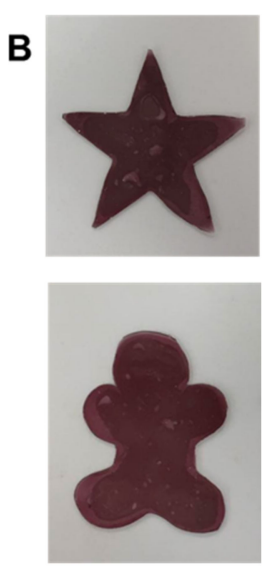

Figure 4. Representative digital and SEM images of polymeric films with GnRs (A). Polymeric films cut before crosslinking (B) (scale bar on digital images represent $1 \mathrm{~cm}$ ).

Table 2. Physical characterization of films loaded with GnRs (mean $\pm S D, n=3$ ).

\begin{tabular}{cccc}
\hline Sample & Thickness $(\mathbf{m m})$ & Area $\left(\mathbf{c m}^{2}\right)$ & Weight $(\mathbf{g})$ \\
\hline CTAB-GnRs & $0.61 \pm 0.12$ & $1.40 \pm 0.18$ & $0.10 \pm 0.03$ \\
PEG-GnRs & $0.60 \pm 0.08$ & $1.80 \pm 0.17$ & $0.12 \pm 0.01$ \\
Control & $0.64 \pm 0.05$ & $1.26 \pm 0.08$ & $0.11 \pm 0.01$ \\
\hline
\end{tabular}

To investigate whether or not GnRs could have an effect on the mechanical properties of polymeric films, a texture analyzer was used to assess force at the break. Results for this test are shown in Figure 5. When a force of around $30 \mathrm{~N}$ was exerted on control films, they broke. Similarly, films including either CTAB or PEG-GnRs showed no significant difference $(p<0.05)$ in this value, suggesting that crosslinking of acid groups of poly(methyl vinyl ether-maleic acid) with alcohol groups of poly(ethylene glycol) was not altered by the presence of GnRs. 


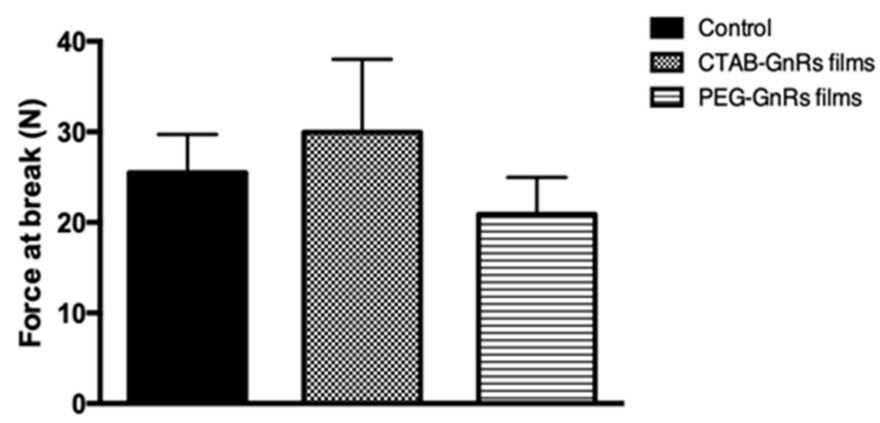

Figure 5. Force at the break of polymeric films (mean $\pm S D, n=6$ ).

When films were placed in contact with porcine skin, it was seen that no adhesion took place, since only $0.60 \mathrm{~N}$ was required in all films (control, CTAB, or PEG-GnRs films) for them to be detached, even after 2 min of being in contact with an applied force of $5 \mathrm{~N}$ (Figure 6). Significant differences in the detachment force between control and GnR-loaded films were not observed $(p>0.05)$.

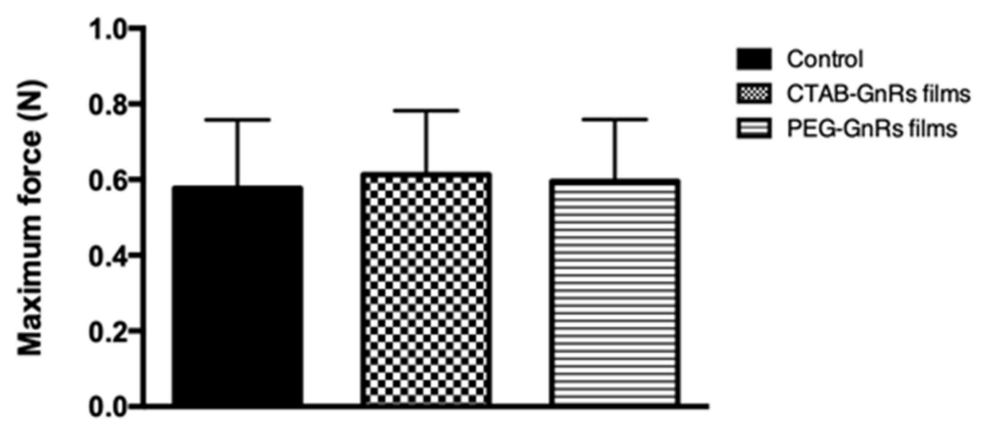

Figure 6. Adhesion studies of polymeric films in neonate porcine skin, where the maximum detachment force was recorded (mean $\pm S D, n=3$ ).

Films broke into smaller pieces during the swelling studies (Figure 7), and so the percentage of swelling could not be studied. However, pictures at different times show that after 5 and $15 \mathrm{~min}$ of immersion, films did not increase in size significantly. After $15 \mathrm{~min}$, films start breaking into smaller pieces. A low molecular weight crosslinking agent was used, and so a highly crosslinked networked was obtained, however the films were quite thin. Then, when exposed to an excess of water, the structure collapsed and broke. The study presented here aimed to observe the swelling behaviour of films only, and so an excess of water was used; however, the setup does not represent what would happen when the films are placed on top of skin.

DSC curves, showed in Figure 8, obtained for Gantrez ${ }^{\circledR}$ S-97 exhibited a broad peak at $157^{\circ} \mathrm{C}$, which was related to the formation of anhydrides between two acid groups [37,38]. A slight shift to higher temperatures of the Gantrez ${ }^{\circledR}$ S-97 peak can be seen in all films prepared, even in the one prepared only with Gantrez ${ }^{\circledR}$ S-97. This can be attributed to the reaction between alcohol and acid groups, requiring a higher amount of energy to carry on with the reaction [37]. In the case of TGA, it can be seen that PEG 200 Da exhibits a thermal decomposition starting around $160^{\circ} \mathrm{C}$ and finishing around $300{ }^{\circ} \mathrm{C}$, which is similar to values previously reported [39]. For the case of Gantrez ${ }^{\circledR}$ S-97, a significant drop in weight loss can be seen around $175^{\circ} \mathrm{C}$, which was associated with the dehydration of the diacid groups. The second drop, starting around $260^{\circ} \mathrm{C}$, was related to decarboxylation and other degradation reactions [38]. Even though both drops in weight loss can be seen in the different prepared films, it is noticeable that Gantrez ${ }^{\circledR}$ S-97, PEG 200, and GnR films were more thermally stable than Gantrez ${ }^{\circledR}$ S-97 pure films, quite likely due to the crosslinking process, since the Gantrez ${ }^{\circledR}$ S-97 onset temperature at $175^{\circ} \mathrm{C}$ shifted on all those films to around $230{ }^{\circ} \mathrm{C}$. 


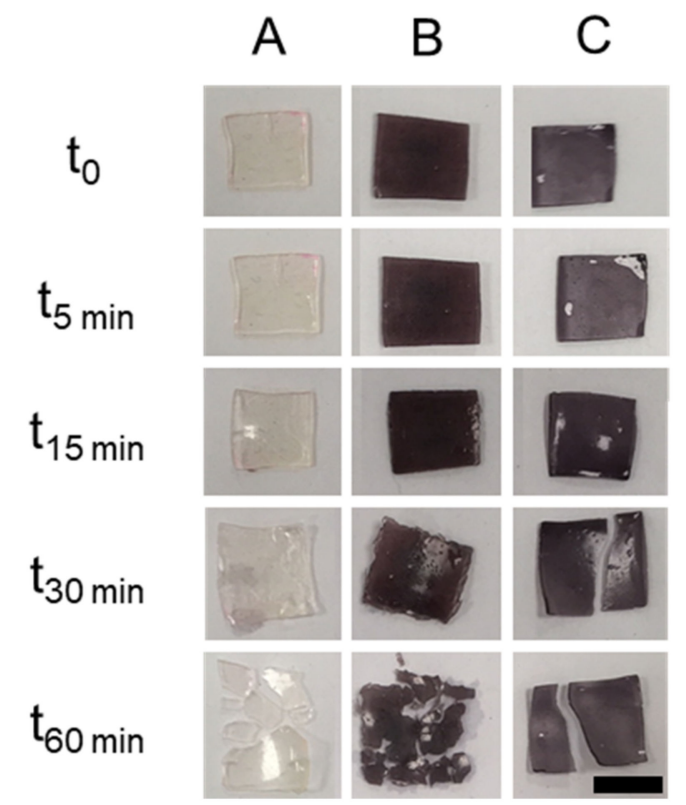

Figure 7. Representative images of films immersed in phosphate buffered saline (PBS) at different times. Control (A), CTAB-GnRs film (B), and PEG-GnRs film (C) (scale bar represents $1 \mathrm{~cm}$ ).

A

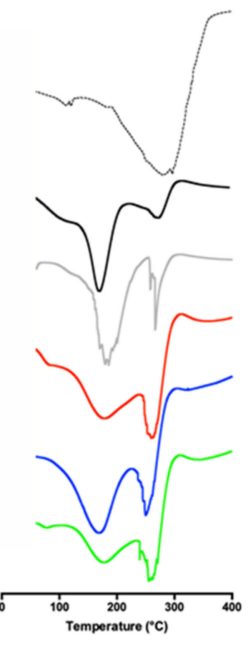

B

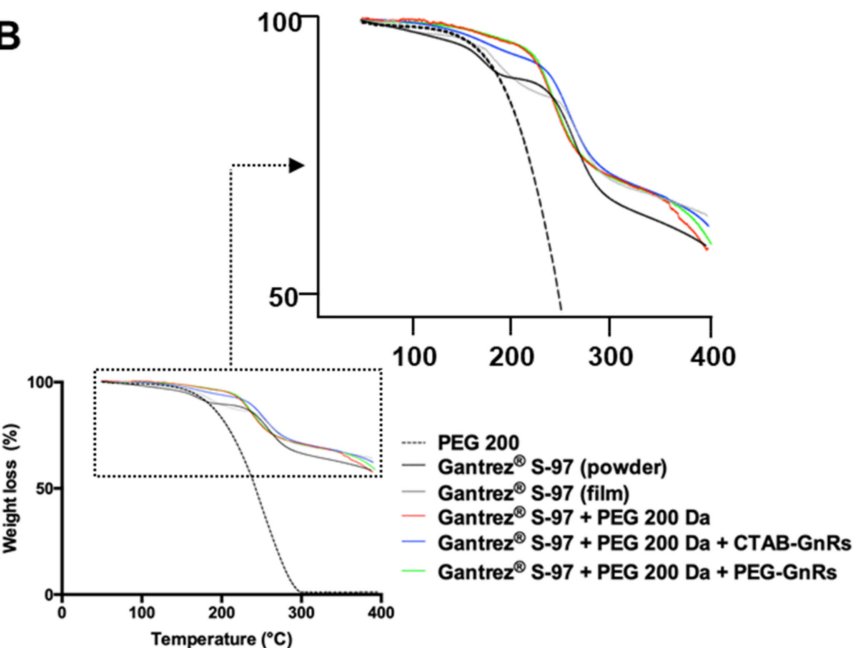

Figure 8. Thermal analysis of PEG $200 \mathrm{Da}$, Gantrez ${ }^{\circledR}$ S-97, and crosslinked films made with CTAB and PEG-GnRs: Differential scanning calorimetry (DSC) (A), thermogravimetric analysis (TGA) (B).

Figure 9A shows the spectra of Gantrez ${ }^{\circledR}$ S-97 powder and films formulated with this excipient, PEG $200 \mathrm{Da}$, and GnRs. When the carbonyl region of the spectrum $\left(2000-1500 \mathrm{~cm}^{-1}\right)$ is observed in detail, it can be seen that both the pure polymer and a film made only from the polymer showed peaks at $1699 \mathrm{~cm}^{-1}$, which can be assigned to the acid carbonyl groups. When the polymer was mixed with PEG $200 \mathrm{Da}$, the peak at 1699 shifted to $1713 \mathrm{~cm}^{-1}$, indicating crosslinking by an esterification reaction between acid groups in Gantrez ${ }^{\circledR}$ S-97 and the terminal hydroxyl groups from the PEG chains. The same peak is appreciated when both CTAB and PEG GnRs where included in the formulation, suggesting that their presence did not affect the crosslinking process. Peaks at 1773 and $1849 \mathrm{~cm}^{-1}$ could be attributed to the formation of anhydride groups between adjacent acid groups in Gantrez ${ }^{\circledR}$ S-97. Furthermore, films were immersed in $\mathrm{NaOH} 5 \mathrm{M}$, dried, and the IR spectrum was once again recorded (Figure 9B). The same aforementioned peak displacement from 1699 to $1713 \mathrm{~cm}^{-1}$ could be seen, but peaks at 1849 and $1773 \mathrm{~cm}^{-1}$ disappeared and were replaced by one at $1563 \mathrm{~cm}^{-1}$, confirming the formation of anhydride groups when films were crosslinked, which then turned into sodium salts $[40,41]$. 

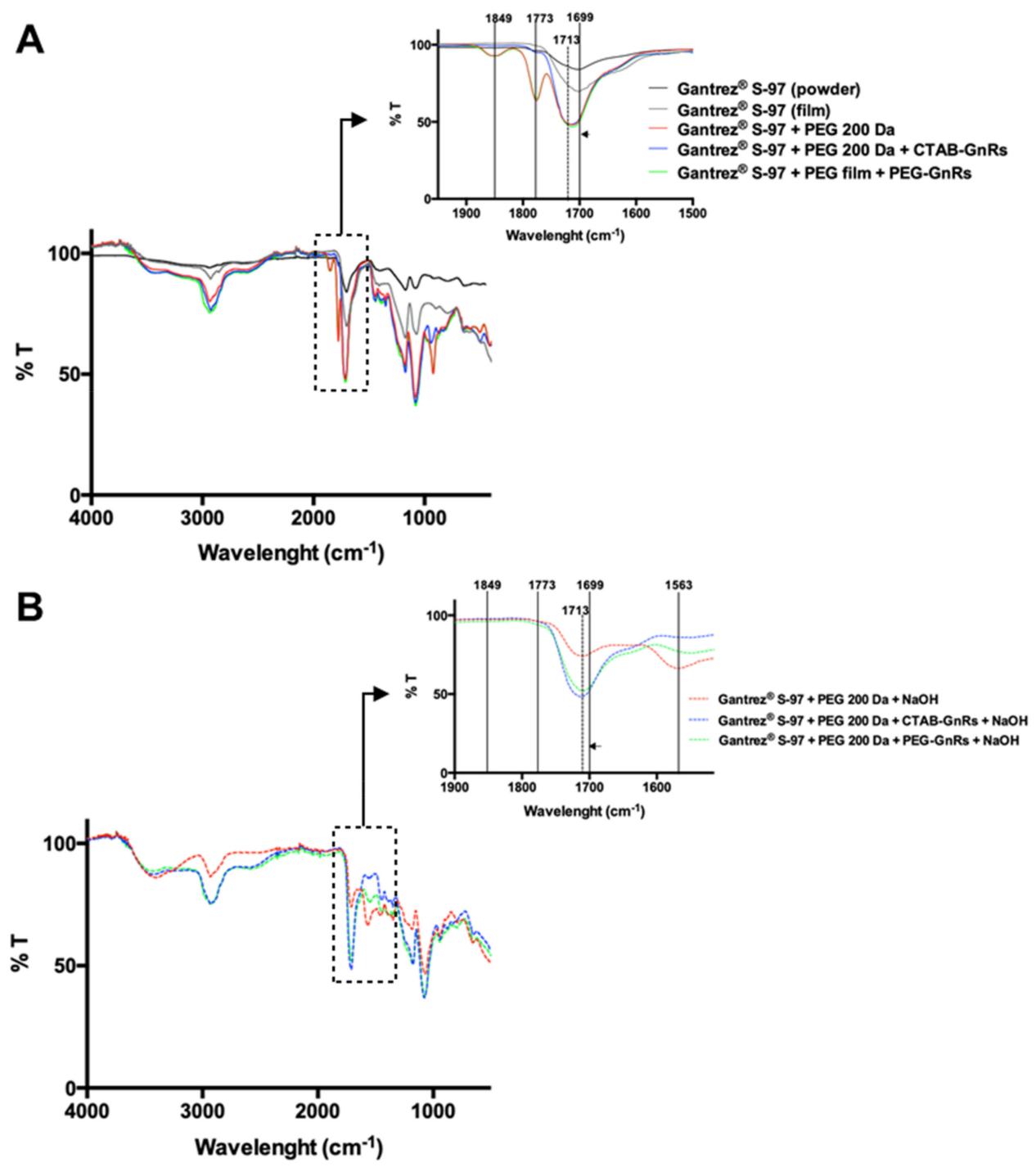

Figure 9. Fourier Transform Infrared Spectroscopy (FT-IR) studies on Gantrez ${ }^{\circledR}$ S-97 (powder) and films before (A) and after immersion into $\mathrm{NaOH}(\mathbf{B})$.

Approaches where the potential of GnRs can be used without exposing the body directly to them should be followed while strong evidence regarding their safety and toxicity is acquired. By including GnRs into a polymeric crosslinked network, there is a high probability of entrapping the particles within. To test this, films were immersed in PBS and left for 5, 15, 30, and $60 \mathrm{~min}$. At each time, films were removed, and the absorbance spectrum of PBS was directly measured, as shown in Figure 10.

A

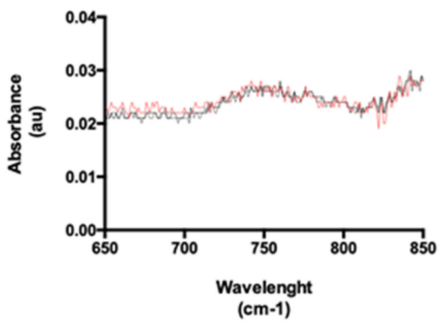

- Control $\mathbf{B}$

Figure 10. Absorbance of PBS after polymeric films were immersed for $5 \mathrm{~min}(\mathbf{A})$ and $1 \mathrm{~h}(\mathbf{B})$.

It can be seen that release of GnRs cannot be differentiated from the control film, as in all cases the maximum absorbance is lower than 0.03 au after 5 min of film immersion on PBS. To further explore this, films were kept up to $1 \mathrm{~h}$ and PBS absorbance was measured. It can be seen that no 
significant changes in absorbance were seen, despite the films being partially disintegrated, as seen before with the swelling studies. This could mean that films are indeed disintegrating due to the excess of PBS, however GnRs remain fully entrapped in the crosslinked network and are not released. Even though the study does not replicate what would exactly happen when a film is placed on top of neonate porcine skin, since an excess of water was used, this supports the idea that GnRs could not be markedly released.

\subsection{Thermal Studies of GnR-Loaded Polymeric Films}

Films were exposed to irradiation using a laser with $2 \mathrm{~W}$ power and a wavelength of $808 \mathrm{~nm}$. Studies were carried out using polymeric films with and without GnRs to determine if the polymeric formulation by itself had a certain degree of thermal conductivity upon laser irradiation. Representative thermal images of the films before and after irradiation are shown in Figure 11.
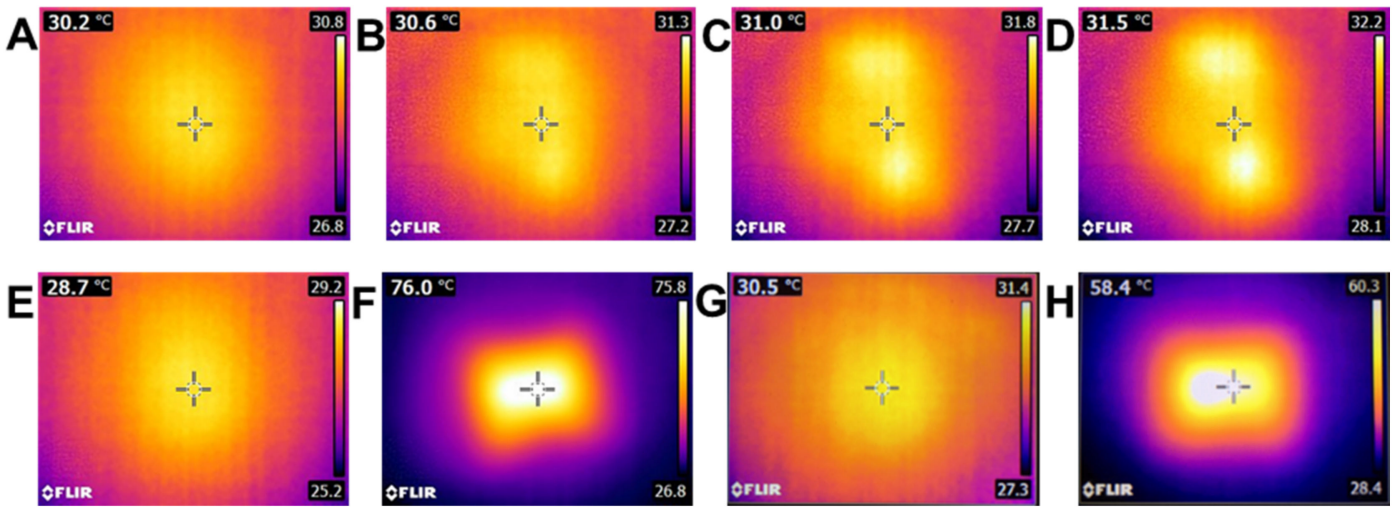

Figure 11. Representative images of temperatures reached by polymeric films with and without GnRs, irradiated with the near-infrared NIR laser. Control film, room temperature and no irradiation (A). Control film after $10 \mathrm{~s}$ of irradiation (B). Control film after $20 \mathrm{~s}$ of irradiation (C). Control film after $30 \mathrm{~s}$ of irradiation (D). CTAB-GnRs film, no irradiation (E). CTAB-GnRs film irradiated for $15 \mathrm{~s}(\mathbf{F})$. PEG-GnRs film, no irradiation (G). PEG-GnRs film irradiated for $15 \mathrm{~s}(\mathbf{H})$.

Films without GnRs exhibited a minimum degree of heating capacity, as even after $30 \mathrm{~s}$ of irradiation the temperature increase was below $2{ }^{\circ} \mathrm{C}$ (Figure 12A). On the other hand, GnRs-loaded films showed a significant increase in temperature. To achieve local hyperthermia, and therefore a biological response of cell death or regeneration, heating cycles may be needed in order to maintain a temperature over $43{ }^{\circ} \mathrm{C}$ for a period of time [42,43]. Therefore, irradiation of polymeric films was conducted for 3 cycles of $10 \mathrm{~s}$ each, followed by cooling until room temperature, and thermal images were taken before and after this to calculate the increase in temperature. In all cases, a similar temperature increase was achieved for the GnR-loaded films, fluctuating around $40{ }^{\circ} \mathrm{C}$ (Figure $12 \mathrm{~B}$ ). Comparisons between each heating cycle for each type of film (either CTAB-GnRs or PEG-GnRs films) showed no statistical differences; hence, films could be irradiated at least three times without increasing or decreasing the temperature that was initially reached. In addition, comparison between CTAB-GnRs and PEG-GnRs at each heating cycle showed no differences either, suggesting that both films can be heated up and can reach the same temperature. It is surprising that both films reached similar temperatures though, since it was shown in the ICP measurements that the suspension of PEG-GnRs had a lower gold concentration than the CTAB one. Hence, PEG-GnRs films had lower concentrations of GnRs. This could suggest that GnR concentration is not the only factor affecting thermal capacity, but also film density, transparency, and thickness, among others. Indeed, the effect of film thickness was further investigated with films with different thicknesses by pouring decreasing amounts of a gel (and so decreasing amount of GnRs) made with PEG-GnRs onto the silicone release liner. As a result, films with thicknesses of $1.06 \pm 0.02,0.81 \pm 0.02$, and $0.60 \pm 0.08 \mathrm{~mm}$ (mean $\pm \mathrm{SD}, \mathrm{n}=3$ ) were obtained and their thermal capacities were compared, as shown in Figure 12C. Despite the fact that the thicker 
film had a higher concentration of GnRs, there was a clear trend between temperature increase and film thickness: the thinner the films, the higher the temperature reached. This could be explained by the laser mainly irradiating the surfaces of the films, and since the structure was so dense and full of GnRs, the laser could not diffuse into the entire exposed film area, affecting the temperature.

A

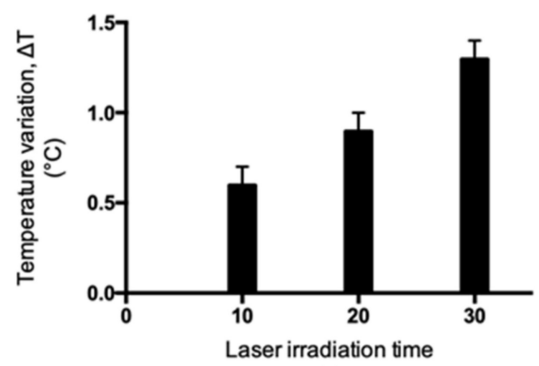

(s)
B

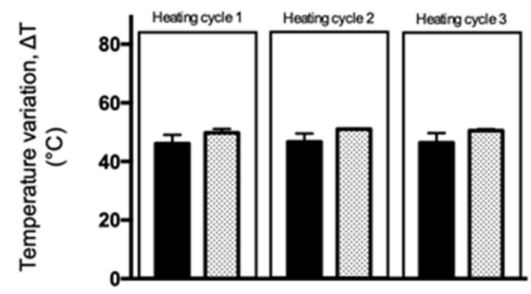

CTAB-GnRs films PEG-GnRs films

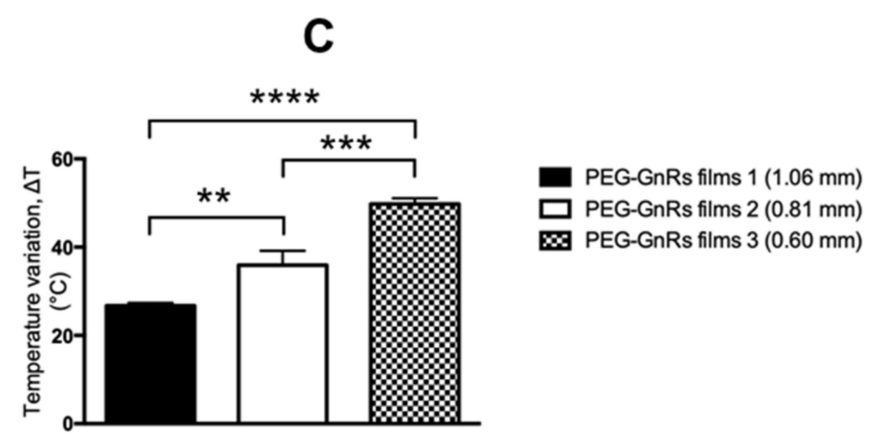

Figure 12. Temperature increase of polymeric film without GnRs irradiated for different times (A). Temperature increase of polymeric films prepared with CTAB and PEG-GnRs. Each film was irradiated for cycles of $15 \mathrm{~s}$, cooled down, and repeated two more times (B). Temperature increase of polymeric films with different thicknesses, prepared using PEG-GnRs (C) (mean \pm SD, $\mathrm{n}=3)(* * p=0.0039$, *** $\left.p=0.0004,{ }^{* * * *} p<0.0001\right)$.

\subsection{Heating Capacity of Polymeric Films on Neonate Porcine Skin}

To prove the potential of films to heat up a biological tissue, two pieces of neonate porcine skin facing each other's dermis were used. To control the temperature reached on the bottom of the skin, a thermocouple wire was used and the temperature recorded before and after irradiation. Figure 13 shows representative thermal images, as well as temperature increase data for the films tested. It can be seen in Figure 13A that control film on top of neonate porcine skin heated up by $1^{\circ} \mathrm{C}$ after $15 \mathrm{~s}$ of irradiation, which correlates to control films being heated only in air, as shown before. On the other hand, porcine skin increased its temperature by around $10{ }^{\circ} \mathrm{C}$ (Figure $13 \mathrm{~B}$ ). This could be attributed to the laser heating the porcine skin up and the film working as a "blanket", keeping the heat. However, after $15 \mathrm{~s}$ of switching off the laser, temperature variation dropped to only $3{ }^{\circ} \mathrm{C}$. When either CTAB or the PEG GnR-loaded films were used, a significant increase in temperature was reached after $15 \mathrm{~s}$ of irradiation, showing the maximum temperature difference of around $35-45^{\circ} \mathrm{C}$ of increase. After switching off the laser, the temperature variation started to drop, but in a very slow manner. After the laser had been switched off, temperature increase ranged between 20 and $30{ }^{\circ} \mathrm{C}$, and $45 \mathrm{~s}$ after, the temperature was still over $12{ }^{\circ} \mathrm{C}$. Even after almost 2 min of the laser being switched off, the temperature increase of porcine skin was about $6{ }^{\circ} \mathrm{C}$. It is important to mention that in all cases, even though $1 \mathrm{~mL}$ of PBS was placed on top of the skin to keep it moist during the studies and to induce contact between the tissue and the films, it did not break during or after laser irradiation. 
A

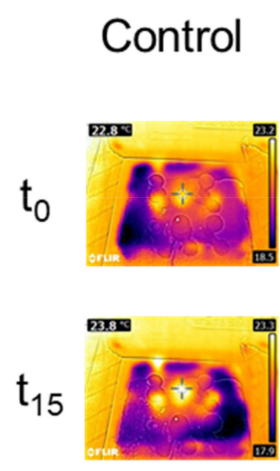

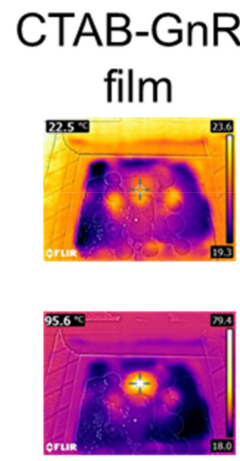

B

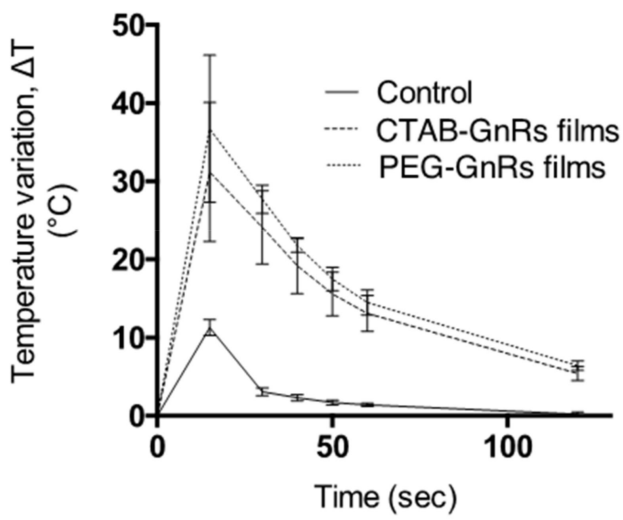

Figure 13. Heating capacity of polymeric films loaded with GnRs on neonate porcine skin. Representative thermal images of films on top of skin after $15 \mathrm{~s}$ of laser irradiation (A). Temperature increase of porcine skin measured with a thermocouple (mean $\pm S D, n=3)(B)$.

\section{Conclusions}

This study demonstrates the potential of GnR-loaded polymeric films to induce superficial hyperthermia upon laser irradiation in a skin model. Inclusion of CTAB and PEG-GnRs in polymeric films did not affect the crosslinking process, or the mechanical or swelling properties. Films could also be cast (or cut before crosslinking) into molds according to the size and shape of skin lesions, offering a tailored treatment for each patient. Body exposure to GnRs will be limited as particles are entrapped in the polymeric network and are not significantly released after swelling of films. This improves the biocompatibility of the material, which is further enhanced by the replacement of CTAB with mPEG-SH. Moreover, as films did not adhere to neonate porcine skin, neither polymeric nor plasmonic material was left behind on the skin.

Heating studies showed that the material's temperature went up to around $45^{\circ} \mathrm{C}$ when films were irradiated with the laser for $15 \mathrm{~s}$, showing the effect of GnRs inclusion on the films, since the temperature of control films did not increase by more than $1.5^{\circ} \mathrm{C}$, even after $30 \mathrm{~s}$ of irradiation. Contrary to what it was expected, it is important to mention film thickness played a major role in the heating capacity and temperature increase in comparison to the GnR cargo. When films were placed on top of neonate porcine skin, the increase of temperature of the skin model went up to around $40^{\circ} \mathrm{C}$ using either CTAB or PEG-GnRs.

These results prove the use of an innovative approach that combines the plasmonic properties of GnRs and a crosslinked hydrogel for less invasive use of GnRs, avoiding injection of the particles and uncertainty regarding their metabolism, safety, and toxicity once they reach systemic circulation. Future studies should focus on studying the effects of GnR-loaded films on murine skin models of non-melanoma skin cancer, addressing the temperature increase and irradiation time needed to induce an apoptotic response in each case.

Author Contributions: Conceptualization, A.C.-M. and R.F.D.; methodology, A.C.-M., J.D.-R., M.T.R., and A.S.C.; investigation and formal analysis, A.C.-M., J.D.-R., and B.M.; data curation, A.C.-M. and J.D.-R.; writing, A.C.-M. and J.D.-R.; writing-review and editing, E.L. and R.F.D.; supervision, S.E.J.B. and R.F.D. All authors have read and agreed to the published version of the manuscript.

Funding: The authors gratefully acknowledge the financial support of the SPaRK project at Queen's University Belfast, funded by the European Union's Horizon 2020 scheme under the Marie Skłodowska-Curie grant agreement No 754507. This work was also supported by the Welcome Trust Biomedical Vacation Scholarship (216714/z/19/z) and the Engineering and Physical Sciences Research Council (EP/P034063/1).

Conflicts of Interest: The authors declare no conflict of interest. 


\section{References}

1. Non-melanoma Skin Cancer Statistics. Available online: https://www.cancerresearchuk.org/ health-professional/cancer-statistics/statistics-by-cancer-type/non-melanoma-skin-cancer. (accessed on 28 Novemeber 2019).

2. Rudolph, C.; Schnoor, M.; Eisemann, N.; Katalinic, A. Incidence trends of nonmelanoma skin cancer in Germany from 1998 to 2010. JDDG J. Dtsch. Dermatol. Ges. 2015, 13, 788-797. [CrossRef] [PubMed]

3. Birch-Johansen, F.; Jensen, A.; Mortensen, L.; Olesen, A.B.; Kjaer, S.K. Trends in the incidence of nonmelanoma skin cancer in Denmark 1978-2007: Rapid incidence increase among young Danish women. Int. J. Cancer 2010, 127, 2190-2198. [CrossRef] [PubMed]

4. Tran, D.A.; Coronado, A.C.; Sarker, S.; Alvi, R. Estimating health care costs of non-melanoma skin cancer in saskatchewan using physician billing data. Curr. Oncol. 2019, 26, 114. [CrossRef] [PubMed]

5. Rogers, H.W.; Weinstock, M.A.; Harris, A.R.; Hinckley, M.R.; Feldman, S.R.; Fleischer, A.B.; Coldiron, B.M. Incidence estimate of nonmelanoma skin cancer in the United States, 2006. Arch. Dermatol. 2010, 146, $283-287$. [CrossRef]

6. Perera, E.; Gnaneswaran, N.; Staines, C.; Win, A.K.; Sinclair, R. Incidence and prevalence of non-melanoma skin cancer in Australia: A systematic review. Australas. J. Dermatol. 2015, 56, 258-267. [CrossRef] [PubMed]

7. Mofidi, A.; Tompa, E.; Spencer, J.; Kalcevich, C.; Peters, C.E.; Kim, J.; Song, C.; Mortazavi, S.B.; Demers, P.A. The economic burden of occupational non-melanoma skin cancer due to solar radiation. J. Occup. Environ. Hyg. 2018, 15, 481-491. [CrossRef]

8. Pondicherry, A.; Martin, R.; Meredith, I.; Rolfe, J.; Emanuel, P.; Elwood, M. The burden of non-melanoma skin cancers in Auckland, New Zealand. Australas. J. Dermatol. 2018, 59, 210-213. [CrossRef]

9. Cakir, B.Ö.; Adamson, P.; Cingi, C. Epidemiology and economic burden of nonmelanoma skin cancer. Facial Plast. Surg. Clin. N. Am. 2012, 20, 419-422. [CrossRef]

10. Bahner, J.D.; Bordeaux, J.S. Non-melanoma skin cancers: Photodynamic therapy, cryotherapy, 5-fluorouracil, imiquimod, diclofenac, or what? Facts and controversies. Clin. Dermatol. 2013, 31, 792-798. [CrossRef]

11. Newlands, C.; Currie, R.; Memon, A.; Whitaker, S.; Woolford, T. Non-melanoma skin cancer: United Kingdom National Multidisciplinary Guidelines. J. Laryngol. Otol. 2016, 130, S125-S132. [CrossRef]

12. Fahradyan, A.; Howell, A.; Wolfswinkel, E.; Tsuha, M.; Sheth, P.; Wong, A. Updates on the management of non-melanoma skin cancer (NMSC). Healthcare 2017, 5, 82. [CrossRef] [PubMed]

13. Micali, G.; Lacarrubba, F.; Bhatt, K.; Nasca, M.R. Medical approaches to non-melanoma skin cancer. Expert Rev. Anticancer Ther. 2013, 13, 1409-1421. [CrossRef] [PubMed]

14. Moy, A.J.; Tunnell, J.W. Combinatorial immunotherapy and nanoparticle mediated hyperthermia. Adv. Drug Deliv. Rev. 2017, 114, 175-183. [CrossRef]

15. Beik, J.; Abed, Z.; Ghoreishi, F.S.; Hosseini-Nami, S.; Mehrzadi, S.; Shakeri-Zadeh, A.; Kamrava, S.K. Nanotechnology in hyperthermia cancer therapy: From fundamental principles to advanced applications. J. Control. Release 2016, 235, 205-221. [CrossRef] [PubMed]

16. Ali, M.R.K.; Rahman, M.A.; Wu, Y.; Han, T.; Peng, X.; Mackey, M.A.; Wang, D.; Shin, H.J.; Chen, Z.G.; Xiao, H.; et al. Efficacy, long-term toxicity, and mechanistic studies of gold nanorods photothermal therapy of cancer in xenograft mice. Proc. Natl. Acad. Sci. USA 2017, 114, E3110-E3118. [CrossRef] [PubMed]

17. Pattani, V.P.; Shah, J.; Atalis, A.; Sharma, A.; Tunnell, J.W. Role of apoptosis and necrosis in cell death induced by nanoparticle-mediated photothermal therapy. J. Nanopart. Res. 2015, 17, 20. [CrossRef]

18. Seo, B.; Lim, K.; Kim, S.S.; Oh, K.T.; Lee, E.S.; Choi, H.-G.; Shin, B.S.; Youn, Y.S. Small gold nanorods-loaded hybrid albumin nanoparticles with high photothermal efficacy for tumor ablation. Colloids Surf. B Biointerfaces 2019, 179, 340-351. [CrossRef]

19. Tiwari, P.; Vig, K.; Dennis, V.; Singh, S. Functionalized gold nanoparticles and their biomedical applications. Nanomaterials 2011, 1, 31-63. [CrossRef]

20. Liao, H.; Hafner, J.H. Gold nanorod bioconjugates. Chem. Mater. 2005, 17, 4636-4641. [CrossRef]

21. Schaeublin, N.M.; Braydich-Stolle, L.K.; Maurer, E.I.; Park, K.; MacCuspie, R.I.; Afrooz, A.R.M.N.; Vaia, R.A.; Saleh, N.B.; Hussain, S.M. Does shape matter? Bioeffects of gold nanomaterials in a human skin cell model. Langmuir 2012, 28, 3248-3258. [CrossRef] 
22. Ye, X.; Zheng, C.; Chen, J.; Gao, Y.; Murray, C.B. Using binary surfactant mixtures to simultaneously improve the dimensional tunability and monodispersity in the seeded growth of gold nanorods. Nano Lett. 2013, 13, 765-771. [CrossRef] [PubMed]

23. Wan, J.; Wang, J.-H.; Liu, T.; Xie, Z.; Yu, X.-F.; Li, W. Surface chemistry but not aspect ratio mediates the biological toxicity of gold nanorods in vitro and in vivo. Sci. Rep. 2015, 5, 11398. [CrossRef] [PubMed]

24. Obaidat, I.; Issa, B.; Haik, Y. Magnetic properties of magnetic nanoparticles for efficient hyperthermia. Nanomaterials 2015, 5, 63-89. [CrossRef] [PubMed]

25. Nunes, Á.M.; da Silva, K.R.M.; Calado, C.M.S.; Saraiva, K.L.A.; Figueiredo, R.C.B.; Leite, A.C.R.; Meneghetti, M.R. Evaluation of gold nanorods toxicity on isolated mitochondria. Toxicology 2019, 413, 24-32. [CrossRef]

26. Alkilany, A.M.; Shatanawi, A.; Kurtz, T.; Caldwell, R.B.; Caldwell, R.W. Toxicity and cellular uptake of gold nanorods in vascular endothelium and smooth muscles of isolated rat blood vessel: Importance of surface modification. Small 2012, 8, 1270-1278. [CrossRef]

27. Alkilany, A.M.; Thompson, L.B.; Boulos, S.P.; Sisco, P.N.; Murphy, C.J. Gold nanorods: Their potential for photothermal therapeutics and drug delivery, tempered by the complexity of their biological interactions. Adv. Drug Deliv. Rev. 2012, 64, 190-199. [CrossRef]

28. Jin, N.; Zhang, Q.; Yang, M.; Yang, M. Detoxification and functionalization of gold nanorods with organic polymers and their applications in cancer photothermal therapy. Microsc. Res. Tech. 2019, 82, 670-679. [CrossRef]

29. Borgheti-Cardoso, L.N.; Viegas, J.S.R.; Silvestrini, A.V.P.; Caron, A.L.; Praça, F.G.; Kravicz, M.; Bentley, M.V.L.B. Nanotechnology approaches in the current therapy of skin cancer. Adv. Drug Deliv. Rev. 2020. [CrossRef]

30. Zhang, Z.; Lin, M. Fast loading of PEG-SH on CTAB-protected gold nanorods. RSC Adv. 2014, 4, 17760. [CrossRef]

31. González-Vázquez, P.; Larrañeta, E.; McCrudden, M.T.C.; Jarrahian, C.; Rein-Weston, A.; Quintanar-Solares, M.; Zehrung, D.; McCarthy, H.; Courtenay, A.J.; Donnelly, R.F. Transdermal delivery of gentamicin using dissolving microneedle arrays for potential treatment of neonatal sepsis. J. Control. Release 2017, 265, 30-40. [CrossRef]

32. Leng, Y.; Yin, X.; Hu, F.; Zou, Y.; Xing, X.; Li, B.; Guo, Y.; Ye, L.; Lu, Z. High-yield synthesis and fine-tuning aspect ratio of (200) faceted gold nanorods by the pH-adjusting method. RSC Adv. 2017, 7, 25469-25474. [CrossRef]

33. Wawra, S.E.; Pflug, L.; Thajudeen, T.; Kryschi, C.; Stingl, M.; Peukert, W. Determination of the two-dimensional distributions of gold nanorods by multiwavelength analytical ultracentrifugation. Nat. Commun. 2018, 9, 4898. [CrossRef] [PubMed]

34. Huang, X.; Neretina, S.; El-Sayed, M.A. Gold nanorods: From synthesis and properties to biological and biomedical applications. Adv. Mater. 2009, 21, 4880-4910. [CrossRef] [PubMed]

35. Orendorff, C.J.; Murphy, C.J. Quantitation of metal content in the silver-assisted growth of gold nanorods. J. Phys. Chem. B 2006, 110, 3990-3994. [CrossRef] [PubMed]

36. Canonico-May, S.A.; Beavers, K.R.; Melvin, M.J.; Alkilany, A.M.; Duvall, C.L.; Stone, J.W. High conversion of $\mathrm{HAuCl} 4$ into gold nanorods: A re-seeding approach. J. Colloid Interface Sci. 2016, 463, 229-232. [CrossRef]

37. Larrañeta, E.; Henry, M.; Irwin, N.J.; Trotter, J.; Perminova, A.A.; Donnelly, R.F. Synthesis and characterization of hyaluronic acid hydrogels crosslinked using a solvent-free process for potential biomedical applications. Carbohydr. Polym. 2018, 181, 1194-1205. [CrossRef]

38. Chung, K.H.; Wu, C.S.; Malawer, E.G. Glass transition temperatures of poly (methyl vinyl ether-co-maleic anhydride) (PMVEMA) and poly (methyl vinyl ether-co-maleic acid) (PMVEMAC) and the kinetics of dehydration of PMVEMAC by thermal analysis. J. Appl. Polym. Sci. 1990, 41, 793-803. [CrossRef]

39. Kou, Y.; Wang, S.; Luo, J.; Sun, K.; Zhang, J.; Tan, Z.; Shi, Q. Thermal analysis and heat capacity study of polyethylene glycol (PEG) phase change materials for thermal energy storage applications. J. Chem. Thermodyn. 2019, 128, 259-274. [CrossRef]

40. Domínguez-Robles, J.; Peresin, M.S.; Tamminen, T.; Rodríguez, A.; Larrañeta, E.; Jääskeläinen, A.-S. Lignin-based hydrogels with "super-swelling" capacities for dye removal. Int. J. Biol. Macromol. 2018, 115, 1249-1259. [CrossRef] 
41. Larrañeta, E.; Lutton, R.E.M.; Brady, A.J.; Vicente-Pérez, E.M.; Woolfson, A.D.; Thakur, R.R.S.; Donnelly, R.F. Microwave-assisted preparation of hydrogel-forming microneedle arrays for transdermal drug delivery applications. Macromol. Mater. Eng. 2015, 300, 586-595. [CrossRef]

42. Lu, C.-H.; Chen, W.-T.; Hsieh, C.-H.; Kuo, Y.-Y.; Chao, C.-Y. Thermal cycling-hyperthermia in combination with polyphenols, epigallocatechin gallate and chlorogenic acid, exerts synergistic anticancer effect against human pancreatic cancer PANC-1 cells. PLoS ONE 2019, 14, e0217676. [CrossRef] [PubMed]

43. Chen, W.; Sun, Y.; Lu, C.; Chao, C. Thermal cycling as a novel thermal therapy to synergistically enhance the anticancer effect of propolis on PANC-1 cells. Int. J. Oncol. 2019, 55, 617-628. [CrossRef] [PubMed]

(C) 2020 by the authors. Licensee MDPI, Basel, Switzerland. This article is an open access article distributed under the terms and conditions of the Creative Commons Attribution (CC BY) license (http://creativecommons.org/licenses/by/4.0/). 